\title{
AIP mutations in Brazilian patients with sporadic pituitary adenomas: a single-center evaluation
}

\author{
Paula Bruna Araujo ${ }^{1,2}$, Leandro Kasuki ${ }^{1,3,4}$, Carlos Henrique de Azeredo Lima5, \\ Liana Ogino ${ }^{5}$, Aline H S Camacho ${ }^{6,7}$, Leila Chimelli ${ }^{6}$, Márta Korbonits ${ }^{8}$ and \\ Monica RGadelha ${ }^{1,5,3}$
}

\begin{abstract}
'Department of Internal Medicine and Endocrine Unit, Medical School and Hospital Universitário Clementino Fraga Filho, Universidade Federal do Rio de Janeiro, Rio de Janeiro, Rio de Janeiro, Brazil 2Diagnósticos da América SA, Rio de Janeiro, Rio de Janeiro, Brazil

${ }^{3}$ Neuroendocrinology Unit, Instituto Estadual do Cérebro Paulo Niemeyer, Rio de Janeiro, Rio de Janeiro, Brazil ${ }^{4}$ Endocrinology Unit, Hospital Federal de Bonsucesso, Rio de Janeiro, Rio de Janeiro, Brazil

${ }^{5}$ Molecular Genetics Laboratory, Instituto Estadual do Cérebro Paulo Niemeyer, Rio de Janeiro, Rio de Janeiro, Brazil ${ }^{6}$ Neuropathology Laboratory Instituto Estadual do Cérebro Paulo Niemeyer, Rio de Janeiro, Rio de Janeiro, Brazil ${ }^{7}$ National Cancer Institute, Rio de Janeiro, Rio de Janeiro, Brazil

${ }^{8}$ Centre for Endocrinology, William Harvey Research Institute, Barts and The London School of Medicine, Queen Mary University of London, Charterhouse Square, London, UK
\end{abstract}

\section{Endocrine CONNECTIONS}

Correspondence should be addressed to P B Araujo or M R Gadelha Email paulabruna@gmail.com or mgadelha@hucff.ufrj.br

\begin{abstract}
Aryl hydrocarbon receptor-interacting protein (AIP) gene mutations (AIPmut) are the most frequent germline mutations found in apparently sporadic pituitary adenomas (SPA). Our aim was to evaluate the frequency of AIPmut among young Brazilian patients with SPA. We performed an observational cohort study between 2013 and 2016 in a single referral center. AIPmut screening was carried out in 132 SPA patients with macroadenomas diagnosed up to 40 years or in adenomas of any size diagnosed until 18 years of age. Twelve tumor samples were also analyzed. Leukocyte DNA and tumor tissue DNA were sequenced for the entire AIP-coding region for evaluation of mutations. Eleven (8.3\%) of the 132 patients had AIPmut, comprising 9/74 (12\%) somatotropinomas, $1 / 38(2.6 \%)$ prolactinoma, $1 / 10(10 \%)$ corticotropinoma and no non-functioning adenomas. In pediatric patients ( $\leq 18$ years), AIPmut frequency was $13.3 \%(2 / 15)$. Out of the 5 patients with gigantism, two had AIPmut, both truncating mutations. The Y268* mutation was described in Brazilian patients and the K273Rfs*30 mutation is a novel mutation in our patient. No somatic AIP mutations were found in the 12 tumor samples. A tumor sample from an acromegaly patient harboring the A299V AIPmut showed loss of heterozygosity. In conclusion, AIPmut frequency in SPA Brazilian patients is similar to other populations. Our study identified two mutations exclusively found in Brazilians and also shows, for the first time, loss of heterozygosity in tumor DNA from an acromegaly patient harboring the A299V AIPmut. Our findings corroborate previous observations that AIPmut screening should be performed in young patients with SPA.
\end{abstract}

\author{
Key Words \\ - AIP \\ - germline mutations \\ - sporadic pituitary \\ adenomas \\ - tumor suppressor gene
} $\begin{array}{lr}\text { http://www.endocrineconnections.org } & \text { ○ } 2017 \text { The authors } \\ \text { DOI: } 10.1530 / E C-17-0237 & \text { Published by Bioscientifica Ltd }\end{array}$

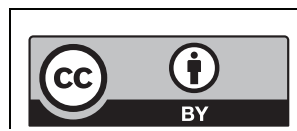

This work is licensed under a Creative Commons Attribution 4.0 International License.
Endocrine Connections (2017) 6, 914-925 


\section{Introduction}

Although most pituitary adenomas occur sporadically, with only $5 \%$ of all cases being related to inherited syndromes (1), the mechanisms underlying pituitary tumorigenesis in a non-familial setting are poorly understood. Somatic mutations and other genetic and/or epigenetic abnormalities have been related to SPA, but a minor subgroup of these adenomas can have a germline mutation in a predisposing gene with no known familial history of pituitary adenoma (2). Germline aryl hydrocarbon receptor-interacting protein (AIP) gene mutations (AIPmut) were first described by Vierimaa and coworkers in 2006 (3). This study has found AIPmut in seemingly sporadic acromegaly patients and in familial isolated pituitary adenomas (FIPA) (3), which is characterized by the presence of pituitary adenomas in two or more members of the same family in the absence of other syndromic clinical features.

AIP appears to act as a tumor suppressor gene (TSG) (3). It is a cytoplasmic protein and a co-chaperone of heat-shock protein 90 (HSP90), and several studies demonstrated the involvement of AIP in various nuclear receptor signaling pathways, such as in estrogen receptor $\alpha$ (ERA) and glucocorticoid receptor (GR) signaling pathways $(4,5,6)$. However, the exact molecular mechanisms by which AIPmut promotes pituitary adenomas are unclear. There is evidence that a failure to inhibit cyclic adenosine monophosphate (cAMP) synthesis underlies the development of pituitary adenomas in AIPmut patients (7). The observation of loss of heterozygosity (LOH) at the chromosome 11q13 in pituitary adenomas containing AIPmut provides another argument for the role of these genetic mutations in pituitary tumorigenesis $(3,8)$. Functional evaluation of AIPmut has shown reduced ability to inhibit cell proliferation and disruption of the protein-protein interaction between AIP and phosphodiesterase-4A5 (PDE4A5) (9). In addition, the observation that most pathological mutations lead to a truncated protein, mostly affecting its C-terminal part, which is involved in interactions with other proteins, or conformational changes that lead to altered protein stability (10), reinforces the role of AIP as a TSG (11).

A number of studies have investigated the prevalence and the clinical characteristics of patients with all types of apparently SPA and AIPmut $(12,13,14,15,16)$, and so far, it is established that AIPmut are the most frequent germline mutations found in SPA (17). The seemingly low prevalence of AIPmut in apparently sporadic cases is probably due to low penetrance $(20 \%)(14,18)$, as de novo mutations have only been described in 2 patients $(19,20)$. Patients harboring AIPmut are predominantly male (61\%), are young at the time of diagnosis (78\% aged $<30$ years) and tend to have macroadenomas (88\%) with extrasellar extension making curative surgery less likely (21). In case of acromegaly, AIPmut patients have a poor response to medical treatment $(14,21)$. Therefore, recognition of AIPmut positive pituitary adenomas is of clinical importance and family member screening can provide early diagnosis of affected patients not yet diagnosed leading to higher chance of disease control.

The findings of previous studies that investigated the prevalence of germline AIPmut in patients with SPA suggest that screening should be focused on young patients (diagnosed before the age of 30-40 years) with macroadenomas or in patients with any size of tumors diagnosed before age 18 years (22). The studies that applied those criteria have found a prevalence ranging from 2.8 to $11.7 \%(13,14,16,23,24,25)$. Most studies were performed in European populations, and only a few were multicentric $(14,16,26)$. Although prevalence of AIPmut seems to be similar across different ethnicities, new studies can show variations in AIPmut profiles and bring more data from different populations. Thus, we analyzed patients with SPA, with diagnosis up to 40 years, for the presence of AIPmut in our tertiary referral center in Brazil.

\section{Materials and methods}

\section{Subjects}

Consecutive patients with SPA from a single referral center were prospectively enrolled from July 2013 to February 2016. This tertiary referral center is part of a University Hospital established in Rio de Janeiro, which is linked to the single health system of Brazil, receiving referrals from all the State. Inclusion criteria were evidence of macroadenoma (maximal diameter $\geq 10 \mathrm{~mm}$ on pituitary MRI) diagnosed up to 40 years. Patients with diagnosis until 18 years of age (pediatric patients) were included both with micro or macroadenoma. Clinical, laboratory and family history from all subjects was undertaken to exclude familial pituitary adenomas either isolated (FIPA and $\mathrm{X}$-linked acro gigantism) or as a component of other genetic syndromes (e.g. multiple endocrine neoplasia types 1 (MEN1) and 4 (MEN4), Carney complex, familial pheochromocytoma/paraganglioma/pituitary adenoma syndrome) (27). Genomic analyses for the screening of

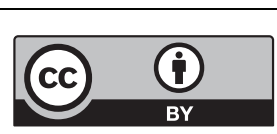

This work is licensed under a Creative Commons Attribution 4.0 International License. 
these genetic syndromes were not performed. All subjects gave written informed consent. The Ethics Committee of the Medical School and the Hospital Universitário Clementino Fraga Filho of the Universidade Federal do Rio de Janeiro (HUCFF-UFRJ) approved the study. Genetic counseling was provided for family members of AIPmut-positive cases, and clinical testing and follow-up were offered, whenever possible.

\section{Pituitary tumor samples}

Formalin-fixed and paraffin-embedded tissue was available from patients who underwent surgery in our center. Histological sections were stained with $\mathrm{H} \& \mathrm{E}$ and submitted to immunohistochemical reactions for pituitary hormones (GH - dilution 1:5000, PRL - dilution 1:5000, ACTH - dilution 1:4000, FSH - dilution 1:3000, TSH - dilution 1:2000, LH - dilution 1:4000), all of them polyclonal rabbit antibody/cell marque. In addition, GH-positive tumors were immunostained with CAM 5.2 (monoclonal mouse antibody cytokeratin (CAM5.2)/Cell Marque, dilution 1:2000) to differentiate sparsely from densely granulated tumors.

Nine frozen and three paraffin-embedded tissue samples of the enrolled patients were available for genetic screening for somatic AIP gene mutations. In cases where AIPmut were identified in leukocyte DNA and tumor DNA was available, search for $\mathrm{LOH}$ was performed through AIP sequencing.

\section{Genomic analyses of AIP}

Mutation screening of AIP was done using genomic DNA isolated from peripheral blood leukocytes and from frozen or paraffin-embedded tumor tissues, using the Gentra PureGene Blood Kit (Qiagen), AllPrep DNA/RNA/miRNA Universal Kit (Qiagen) and QIAamp DNA FFPE Tissue Kit (Qiagen), respectively, following the manufacturer's instructions.

The entire AIP-coding region (exons 1-6) as well as flanking intronic sequences were amplified and sequenced with AIP PCR/sanger sequencing primer pairs (Thermo Fisher Scientific). The promoter region was not analyzed. PCRs were performed on Applied Biosystems ProFlex PCR System (Applied Biosystems). PCR products clean up were performed with ExoSAP-IT (USB Corporation, Cleveland, OH, USA). DNA sequencing was performed using Big Dye Terminator 3.1 Cycle Sequencing kit and an automated capillary sequencer (ABI 3130xl Genetic Analyzer, Applied Biosystems). Electropherogram-derived sequences were compared with NCBI references for the AIP gene (NG_008969.1 RefSeq-Gene and NM_003977.3 transcript) using Benchling (http://benchling.com, Benchling Inc, San Francisco, CA, USA). All genetic alterations were confirmed by a repeated analysis.

AIP sequence variants were compared with human single-nucleotide polymorphism (SNP) databases (dbSNP, http://www.ncbi.nlm.nih.gov/SNP/snp_summary.cgi), ExAC database (http://exac.broadinstitute.org) and also against AIP mutation data from genetically diverse populations (28). Only the variants that met the mutation criterion, defined as a minor allele frequencies (MAF) $<1 \%$, were considered for further analysis (intronic variants outside the splicing site area were not analyzed). PolyPhen2 (http://genetics.bwh.harvard.edu) and Alamut Software, version 2.2e (Interactive Biosoftware, Rouen, France) were used to evaluate the pathogenicity of missense mutations on AIP structure. Mutations were classified as pathogenic, likely pathogenic, variants of uncertain significance (VUS), likely benign or benign, according to the Standards and Guidelines for the Interpretation of Sequence Variants (29).

Patients with somatotropinomas and pediatric patients with any pituitary adenoma in whom AIP sequencing did not find a mutation were screened for large deletions of the AIP using multiplex ligation-dependent probe amplification (Salsa MLPA probemix P244-B1 AIP-MEN1, MRC-Holland, Amsterdam, The Netherlands), whenever suitable quality DNA was available.

\section{Statistical analyses}

Normal distribution was tested by the KolmogorovSmirnov and Shapiro-Wilk tests. The Mann-Whitney $U$ test and the $\chi^{2}$ test were used for statistical analysis. Data are given as median (range). $P$ values below 0.05 were considered as significant.

\section{Results}

\section{Clinical characteristics of the study cohort}

A total of 132 patients with sporadic pituitary macroadenomas diagnosed up to 40 years, and with micro or macroadenomas diagnosed until 18 years of age were included. Of these patients, 74 (56\%) had acromegaly or gigantism, 38 (28.8\%) had prolactinoma, 10 (7.6\%) had non-functioning pituitary adenoma (NFPA) and 10 (7.6\%) had Cushing's disease. The median age at diagnosis was 28

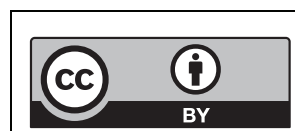

This work is licensed under a Creative Commons Attribution 4.0 International License. 
Table 1 Clinical, radiological and pathological data of the study cohort.

\begin{tabular}{l}
$\begin{array}{l}\text { Type of pituitary tumor and } \\
\text { distribution (Dx until and after } 18 \text { years) }\end{array}$ \\
\hline Somatotropinoma \\
$n=74 ; 56.0 \%$ \\
$\leq 18$ years $=1$ \\
$>18$ years $=73$ \\
Prolactinoma \\
$n=38 ; 28.8 \%$ \\
$\leq 18$ years $=8$ \\
$>18$ years $=30$ \\
NFPA \\
$n=10 ; 7.6 \%$ \\
$\quad \leq 18$ years $=2$ \\
$>18$ years $=8$ \\
Cushing's disease \\
$n=10 ; 7.6 \%$ \\
$\quad \leq 18$ years $=4$ \\
$>18$ years $=6$ \\
Total \\
$n=132$
\end{tabular}

\begin{tabular}{c}
\hline Females $(\%)$ \\
\hline $43(58)$ \\
$1(100)$ \\
$42(58)$ \\
$27(71)$ \\
$5(63)$ \\
$22(73)$ \\
$6(60)$ \\
0 \\
$6(75)$ \\
$8(80)$ \\
$2(50)$ \\
$6(100)$ \\
$84(63)$
\end{tabular}

\begin{tabular}{c}
$\begin{array}{c}\text { Median age } \\
(\text { min-max })\end{array}$ \\
\hline $29(18-40)$ \\
18 \\
$29(20-40)$ \\
$23(11-40)$ \\
$17(11-18)$ \\
$25(19-40)$ \\
$30.5(11-37)$
\end{tabular}

\begin{tabular}{c}
$\begin{array}{c}\text { Median tumor diameter } \\
\text { mm (min-max) }\end{array}$ \\
\hline $24(11-61)$ \\
20 \\
$25(11-61)$ \\
$19(10-81)$ \\
$19(14-60)$ \\
$19.5(10-81)$ \\
$27(12-50)$
\end{tabular}

\begin{tabular}{c}
$\begin{array}{c}\text { Giant adenomas } \\
(\%)\end{array}$ \\
\hline $7(9.4)$ \\
0 \\
7 \\
$12(31.6)$
\end{tabular}

\begin{tabular}{c}
$\begin{array}{c}\text { Available } \\
\text { tumors }\end{array}$ \\
\hline 8 \\
0 \\
8 \\
2 \\
\hline
\end{tabular}

$12.5(11-14)$

$32.5(22-37)$

$21.5(9-39)$

22*

$28.5(12-50)$

$12(6-35)$

$14(9-16)$

$25(21-39)$

$28(9-40)$

$10(6-11)$

$15.5(12-35)$

$22(6-81)$

\begin{tabular}{l}
3 \\
9 \\
$1(10)$ \\
0 \\
1 \\
0 \\
0 \\
0 \\
$20(14.5)$ \\
\hline
\end{tabular}

0

2

0

0

0

2

*Only one patient had tumor diameter available.

Dx, diagnosis; NFPA, non-functioning pituitary adenoma.

(9-40) years, 15 (11.3\%) had diagnosis during childhood or adolescence (age $\leq 18$ years), 84 (63.6\%) were female and the median tumor diameter at diagnosis was 22 (6-81) mm. Characteristics of each group at diagnosis are given in Table 1. Female predominance was seen in all groups.

\section{Patients with AIPmut}

Germline AIPmut were observed in 11 (8.3\%) of the 132 patients. Among these 11 patients, we found 8 different AIPmut (3 pathogenic mutations, 3 VUS and 2 likely benign mutations) (Table 2).

Among the 74 patients with somatotropinomas, 9 (12.2\%) presented AIPmut. From this group, 2 out of 5 patients with gigantism had a pathogenic truncating AIPmut (Y268* and K273Rfs*30) and 7 out of 69 (10.1\%) patients with acromegaly had an AIP VUS or likely benign mutations (Table 2). Dosage analysis by MLPA was possible from 59 of the 65 patients with somatotropinomas without AIPmut, including the 3 patients with gigantism, and did not reveal any large deletions.

The male patient with gigantism harboring the nonsense AIPmut Y268* (c.804C >A), had the diagnosis at 27 years with a history of accelerated growth since the age of 13 years (height at diagnosis $217 \mathrm{~cm}$ ), arthralgia and a $17 \mathrm{~mm}$ macroadenoma. He refused surgery, and treatment with first-generation somatostatin analogue (SA) did not result in normalization of his GH and IGF-1 levels.
Parental DNA from his mother and 2 sisters were available for AIPmut screening, and the same mutation was found in one of the sisters who is clinically unaffected, although a proper evaluation with pituitary hormones and pituitary MRI was not performed due to her refusal (Fig. 1A).

The frameshifit AIPmut K273Rfs*30 (c.816delC) (14) was detected in a 22-year-old female patient who presented with a phenotype of gigantism, height of $181 \mathrm{~cm}$ and a $22 \mathrm{~mm}$ macroadenoma. She underwent a pituitary surgery, and histopathology of the tumor confirmed to be a somatotropinoma. She was started on clinical treatment with first-generation SA and cabergoline (CAB) with poor response, and then was started on pegvisomant. Unfortunately, genetic screening of her family is not available.

The missense likely benign AIPmut R16H (c.47G >A) was found in a male acromegaly patient with diagnosis at the age of 33 years with a macroadenoma of $12 \mathrm{~mm}$. Pituitary surgery was curative and pathology demonstrated a sparsely granulated (SG) somatotropinoma. The other AIP likely benign mutation c. ${ }^{*} 64 \mathrm{G}>\mathrm{A}$, located at the $3^{\prime}$ untranslated region (3'UTR), was found in a male acromegaly patient (Table 2), diagnosed at the age of 38 years with a tumor of $25 \mathrm{~mm}$, in a preoperative evaluation for rhinoplasty. He underwent two pituitary surgeries, and the pathology revealed a SG somatotropinoma. Due to resistance to combined firstgeneration SA and CAB therapy, the patient was started on pasireotide LAR, which resulted in disease control. 


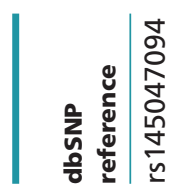

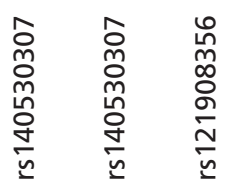

|

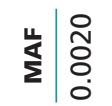

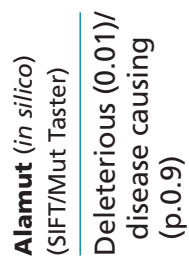

$\stackrel{n}{\Sigma} \quad \frac{n}{\Sigma} \quad \frac{0}{2}$

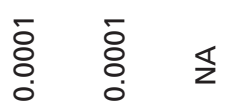

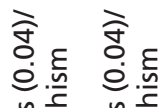

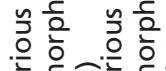

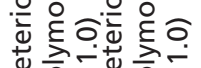

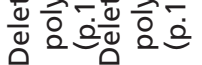

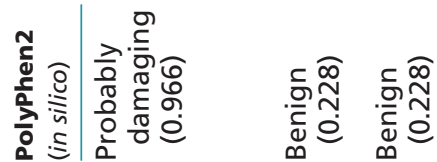

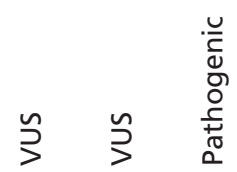

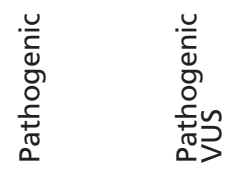

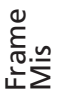

늉

㐔.

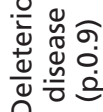

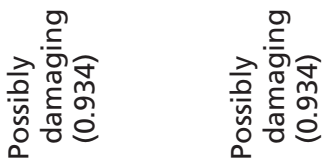

$\stackrel{n}{\zeta}$

$\frac{1}{\sqrt{5}}$
$\frac{0}{0}$
$\frac{0}{0}$
$\frac{0}{0}$
$\frac{5}{2}$ $\frac{8}{\sigma}$
$\frac{0}{0}$
$\frac{0}{0}$
$\frac{0}{n}$

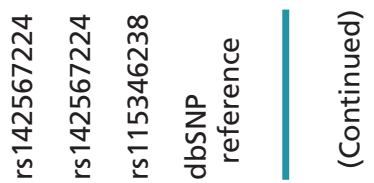

$\stackrel{n}{\Sigma}$

ڤ્oㄹㄴ

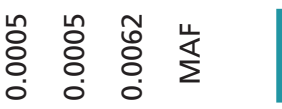

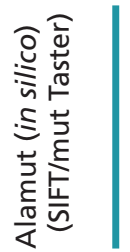

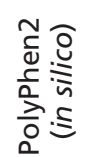

월

¿n

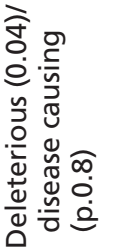

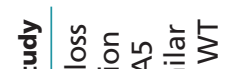

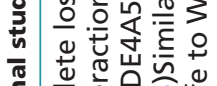

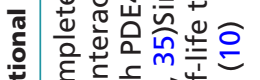

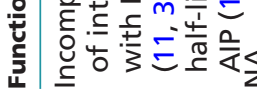

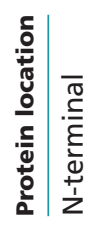

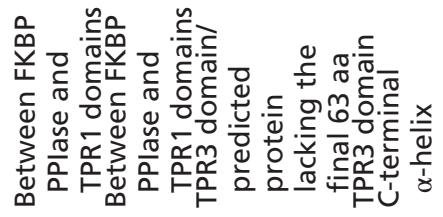

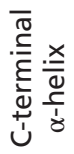

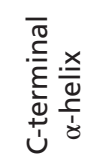

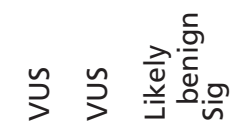

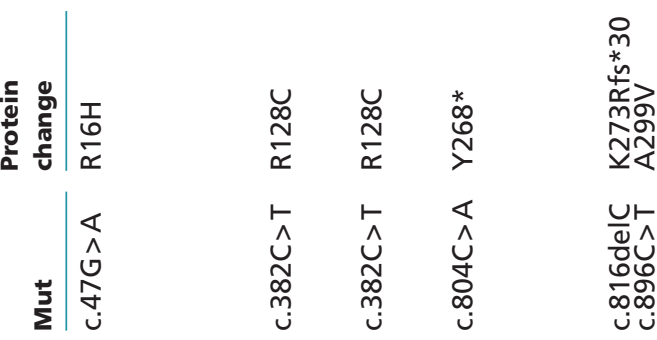

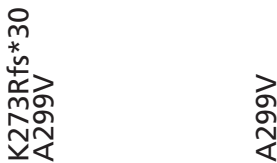

बे गे क्षे

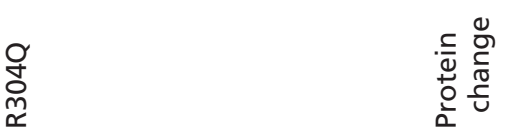

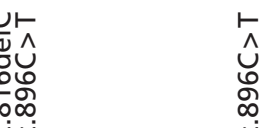

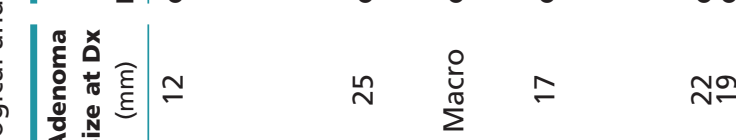

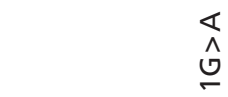

$\stackrel{\wedge}{\grave{\sigma}}$

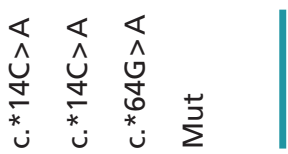

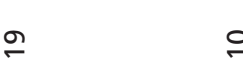

8

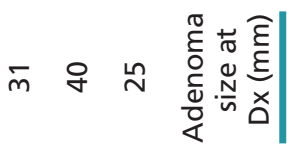

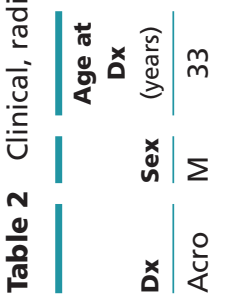

मे

ลำ

$\stackrel{\infty}{\circ}$

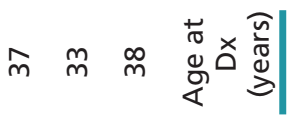

ᄂ $\Sigma \Sigma$ ч $\Sigma$

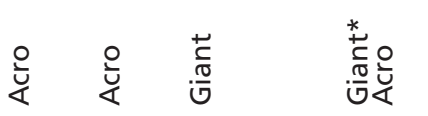

$\Sigma$

เ เ $\Sigma \stackrel{\times}{\curvearrowleft}$

๑

迹学变宕

(c) 2017 The authors DOI: 10.1530/EC-17-0237 


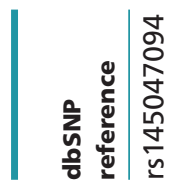

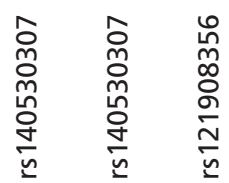

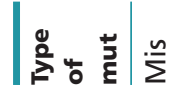

旁营

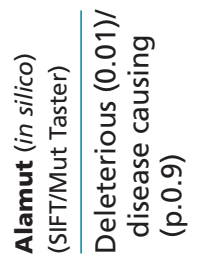

$\stackrel{n}{\Sigma} \quad \frac{n}{\Sigma}$

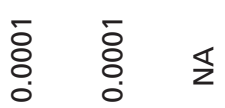

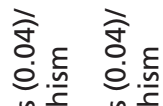

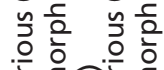

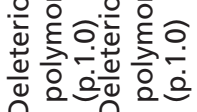

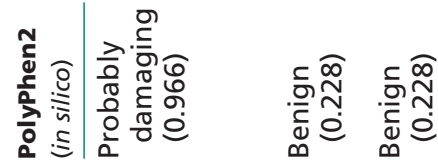

กำ

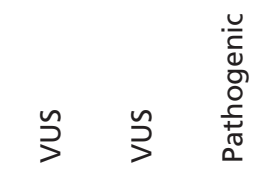

졸 苍. 은 는

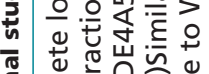

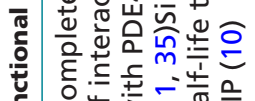

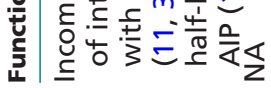

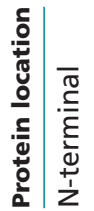

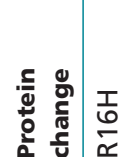

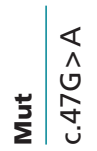

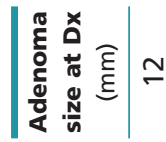

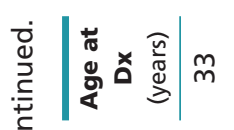

บे

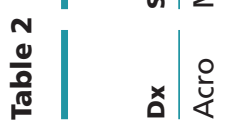

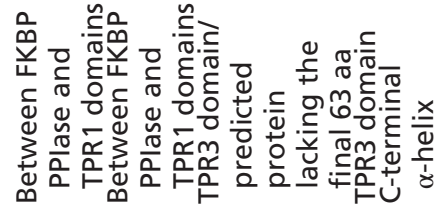

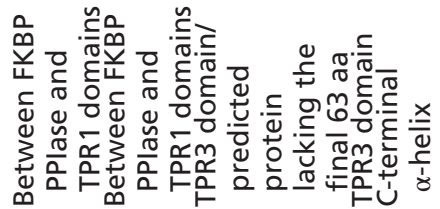

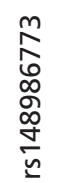

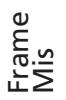

ष๐্े

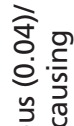

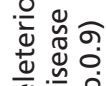

잉

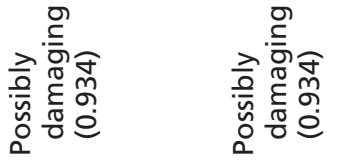

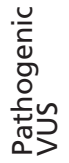

宮

䍏

흔

离要这

$\stackrel{n}{\zeta}$

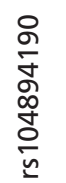

$\stackrel{n}{\Sigma} \quad \stackrel{n}{\Sigma}$

$\Sigma$
Ln
$\vdots$
0

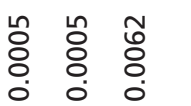

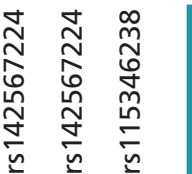

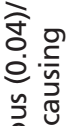

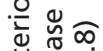

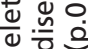

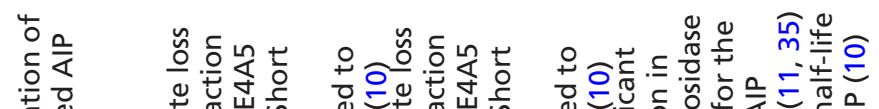

吾焉

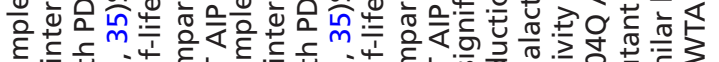

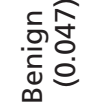

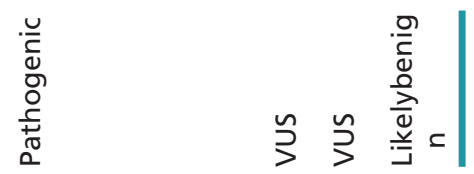

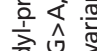

这

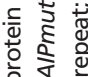

일

흘

客 ญ.

茫

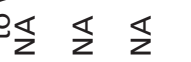

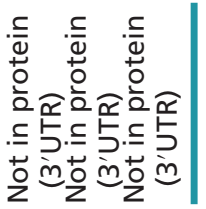

安

离产

年

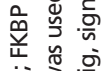

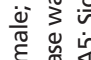

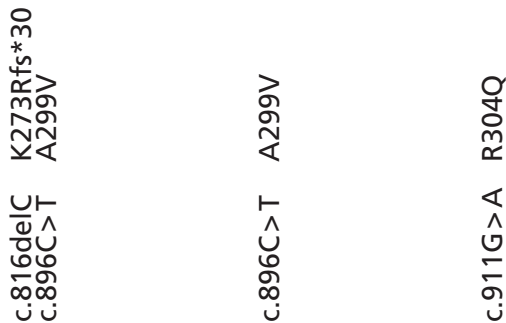

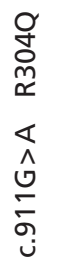

กัด

No

$\stackrel{n}{\circ}$

$\stackrel{\infty}{\circ}$

$\hat{m} \stackrel{m}{m} \stackrel{\infty}{m}$

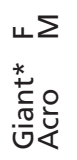

$\Sigma$

$\Sigma$

$\overrightarrow{\underline{\alpha}}$
ᄂ ᄂ $\Sigma \mid \frac{0}{2}$

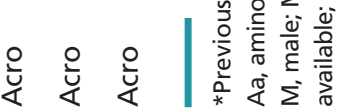

http://www.endocrineconnections.org DOI: 10.1530/EC-17-0237
(๑) 2017 The authors Published by Bioscientifica Ltd

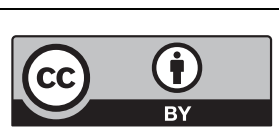

This work is licensed under a Creative Commons Attribution 4.0 International License. 


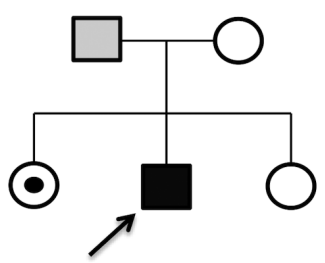

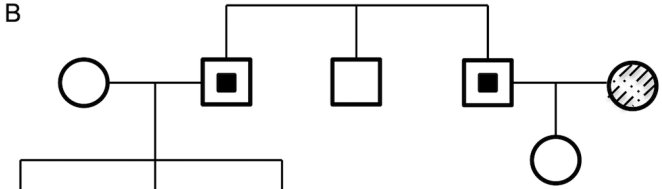

C

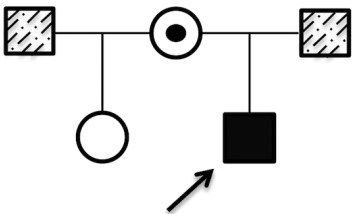

Legend:

$\square$ Tested negative

Affected carrier

Q Unaffected carrier

$\square$ Obligated carrier (not tested)

Untested members
Figure 1

Pedigrees of the families of the probands. The scheme shows the three family trees (A, B and C) of the probands (black squares with an arrow) Male family members are represented by squares, females by circles.
The missense AIP VUS A299V (c.896C > T) was present in a male patient with acromegaly diagnosed at the age of 40 years with a tumor of $19 \mathrm{~mm}$. A non-curative pituitary surgery was performed and the pathology showed a SG somatotropinoma. Medical treatment with firstgeneration SA was started with poor response. The other AIP VUS were found only in acromegaly patients, including c. ${ }^{\star} 14 \mathrm{C}>\mathrm{A}$ (Table 2). The R128C AIPmut was found in one male and one female patient, both diagnosed at the age of 34 years with macroadenomas. Both had non-curative surgeries. The female patient showed resistance to firstgeneration SA therapy, even after radiation therapy and to $\mathrm{CAB}$ association and is now under control with SA and pegvisomant. The male patient had radiotherapy and is under control with first-generation SA treatment.
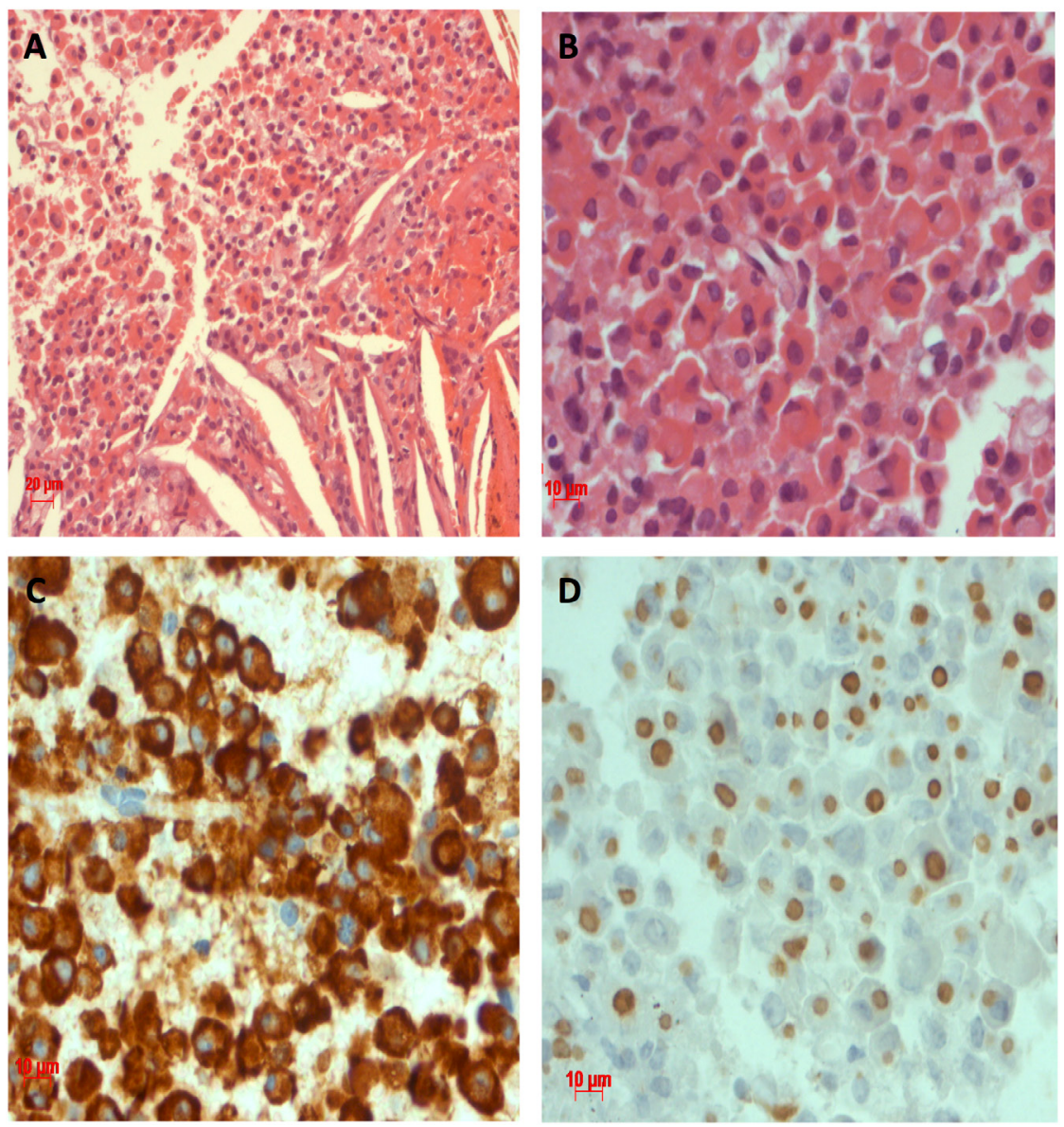

Figure 2

Sparsely granulated somatotropinoma from the patient with the AIPmut c. ${ }^{*} 14$ C $>$ A. Pituitary adenoma stained with Hematoxilin \& Eosin, consisting of eosinophilic cells ( $A$ and $B$ ) and immunopositive for $\mathrm{GH}(\mathrm{C})$, which are sparsely granulated (dot staining) with CAM 5.2 (D). There are blood cells and cholesterol clefts among the epithelial cells (A). http://www.endocrineconnections.org DOI: 10.1530/EC-17-0237
(๑) 2017 The authors Published by Bioscientifica Ltd

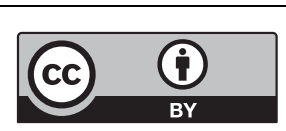

This work is licensed under a Creative Commons Attribution 4.0 International License. 
The c. ${ }^{*} 14 \mathrm{C}>\mathrm{A}$ AIPmut was found in two female patients with acromegaly. The first one was diagnosed at the age of 37 with a tumor of $31 \mathrm{~mm}$ operated transsphenoidally. She had resistance to combined treatment of first-generation $\mathrm{SA}$ and $\mathrm{CAB}$, but achieved control with the combination of SA and pegvisomant. The second one was diagnosed at the age of 33 years with a giant tumor. She was submitted to a pituitary surgery and the pathology showed a SG somatotropinoma (Fig. 2). Medical treatment with firstgeneration SA was started, and the patient did not achieve disease control.

In the 38 patients with prolactinomas, 1 (2.6\%) had the pathogenic AIPmut R304Q (c.911G>A). This male patient was diagnosed in the age of 18 years with a giant adenoma $(60 \mathrm{~mm})$ and very high prolactin (PRL) levels $(20,000 \mathrm{ng} / \mathrm{mL})$. A pituitary surgery was performed, but PRL remained elevated, and he showed resistance to high doses of $\mathrm{CAB}$ (3.5 mg/week). Tumor sample was not available for $\mathrm{LOH}$ analysis, but genetic screening of his family identified his father and paternal uncle as AIPmut carriers, since clinical evaluation, pituitary hormones dosage and pituitary MRI were normal for both relatives (Fig. 1B).

Among the 10 patients with corticotropinomas, 1 (10\%) had the missense AIP VUS A299V (c.896C>T). Cushing's disease was diagnosed in this male patient at the age of 15 years. He had a $10 \mathrm{~mm}$ pituitary adenoma that was surgically resected four times, with immunohistochemistry positive for adrenocorticotrophic hormone (ACTH) and a Ki-67 index of 5\%. As the patient was not cured, a bilateral adrenalectomy was performed for disease control, and he developed Nelson's syndrome 6 months after surgery. The same mutation was found in his clinically unaffected mother, who has presented normal levels of pituitary hormones and a normal pituitary MRI (Fig. 1C). This patient's tissue sample has been tested negative for somatic ubiquitin-specific protease 8 (USP8) gene (30).

No mutations were detected among patients with NFPA. There was no difference regarding age, gender and tumor size at diagnosis between patients harboring or not AIPmut ( $P=0.27, P=0.053$ and $P=0.94$, respectively).

\section{AIPmut in pituitary tumor samples and LOH analysis}

Of the 12 genomic DNA tumor samples from our cohort, 9 were from patients who had no mutation on AIP sequencing of the peripheral blood DNA (6 somatotropinomas, 2 prolactinomas and 1 Cushing's disease). These samples did not show somatic AIP mutations. Among the 3 patients that have shown an AIPmut on the peripheral blood

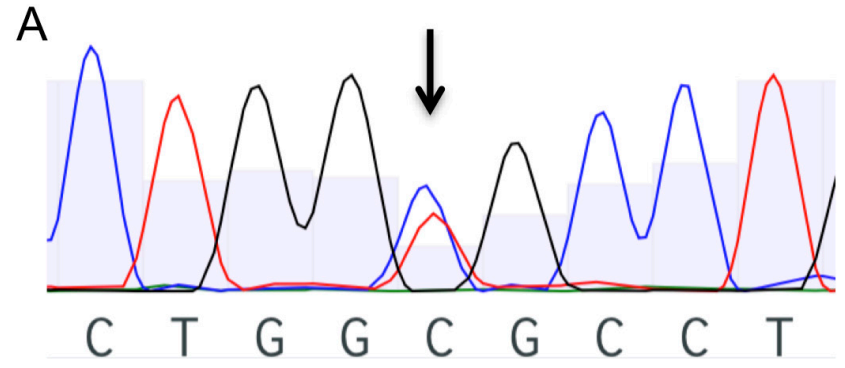

B

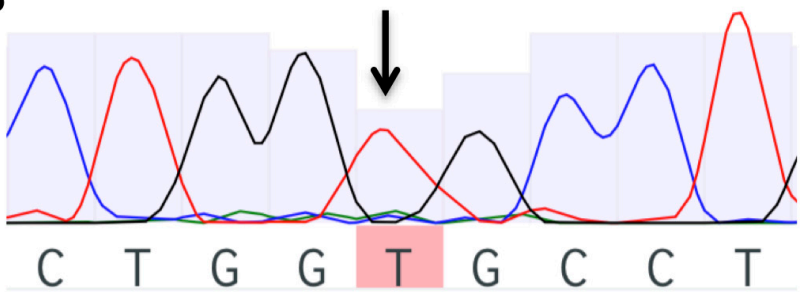

Figure 3

Sequencing electropherograms showing AIPmut c.896C $>$ T (A299V) in exon 6 . Black arrows show the position of the nucleotide change. (A) Blood leukocyte genomic DNA from acromegaly patient. (B) Tumor genomic DNA from acromegaly patient with loss of heterozygosity (LOH).

leukocyte DNA analysis, LOH was investigated through AIP sequencing. $\mathrm{LOH}$ was found in the tumor sample of the acromegaly patient harboring the A299V (c.896C > T) VUS, with loss of the wild-type allele (Fig. 3A and B). No $\mathrm{LOH}$ was identified in the tumor sample from the patient with Cushing's disease harboring the A299V VUS and the patient with acromegaly harboring the c. ${ }^{*} 14 \mathrm{C}>\mathrm{A}$ AIPmut.

\section{AIPmut in pediatric patients with pituitary adenomas}

Considering only pediatric patients, AIPmut were identified in 2 of 15 patients (13.3\%) diagnosed until 18 years of age. The pathogenic AIPmut R304Q was found in one patient with prolactinoma and the AIP VUS A299V was found in one patient with Cushing's disease. Dosage analysis by MLPA was possible from 12 of the 13 pediatric patients without AIPmut and did not reveal any large deletions.

\section{Discussion}

Our finding of AIPmut in 8.3\% of our cohort and in $13.3 \%$ among pediatric patients is consistent with the findings of previous studies in other populations $(13,14,16,24)$. Moreover, our study identified two AIPmut exclusively found in Brazilian patients and also shows, for the first time, LOH in the tumor DNA from an acromegaly patient harboring the A299V AIPmut. Although the

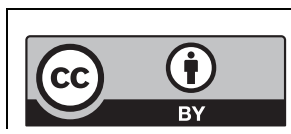

This work is licensed under a Creative Commons Attribution 4.0 International License. 
study has included all types of pituitary adenomas matching the inclusion criteria, the acromegaly group is overrepresented, probably because we are a state referral center for the treatment of acromegaly, and the NFPA group has a limited number of patients; therefore, we cannot draw a definitive conclusion on the prevalence of AIP mutations in this type of adenoma.

Although AIPmut frequency in Brazil has shown to be similar to other populations, there are some interesting aspects of our study. Among the eight different AIPmut found, two out of three pathogenic mutations were never described in other populations. The first one is the nonsense AIPmut Y268*, which has been found in a Brazilian family with acromegaly (31), in a Brazilian patient with familial macroprolactinoma diagnosed in his twenties (18) and in the patient with gigantism presented here and elsewhere (14). This mutation results in a premature TAA-stop signal at codon 268 (31) (Table 2), and a missense mutation at this residue has previously been reported (AIPmut Y268C) (18). Another patient from our center who was diagnosed with acromegaly at 49 years, tested positive for the same AIPmut in another study (32). However, no family relationship between them was found, but a founder effect cannot be excluded. Family members of both patients were screened for the AIPmut Y268* and carriers' relatives were found. The second one is the novel germline frameshift AIPmut K273Rfs*30 predicted to lead to a truncated protein (Table 2 ). This mutation was only described in our patient with gigantism (current study and (14)). Both mutations are located on exon 6, which is the most affected exon of the AIP gene.

The third pathogenic mutation found is the missense mutation R304Q (c.911G >A) (Table 2), first described by Georgitsi and coworkers (33) in a seemingly sporadic case of Cushing's disease. Our study identified this mutation in an 18-year-old patient with a giant prolactinoma resistant to $\mathrm{CAB}$ treatment, with his unaffected father and uncle carrying the same mutation. The pathogenic role of R304Q has been strongly supported by clinical data, since it has been identified in several independent FIPA families as well as in sporadic patients including cases of acromegaly, Cushing's disease and prolactinoma $(9,11$, $12,13,16,24,25,33)$. The c. $911 \mathrm{G}>\mathrm{A}$ is part of a $\mathrm{CpG}$ island mutational hotspot (34) and the missense mutation could possibly affect the interaction of AIP with AhR (33), but functional studies did not show significant reduction in $\beta$-galactosidase activity for the R304Q AIP mutant $(11,35)$ (Table 2). Moreover, the MAF of AIPmut R304Q, provided by ExAC, is very high when compared to other pathogenic or VUS AIPmut (Table 2). Therefore, the higher
MAF together with discrepancies between experimental conditions and clinical data could lead to a review of the classification of the AIPmut R304Q to a likely pathogenic mutation or even to a VUS.

The AIP VUS A299V (Table 2) has been found in patients with acromegaly, prolactinoma and NFPA, both in sporadic and familial cohorts $(11,14,15,20,33)$. None of these studies showed tumor LOH related to this VUS, but there are also no data of this VUS being found in any of the large general population databases. We identified the AIP VUS A299V, in a young patient with Cushing's disease and in a patient with acromegaly resistant to treatment with SA. Both tumor samples were available, and $\mathrm{LOH}$ was found in the somatotropinoma, with retention of the mutated allele, which is in accordance with the Knudson's two-hit hypothesis (36). Therefore, this is the first time that the LOH of the AIP VUS A299V is found in a somatotropinoma supporting the possibility that it might play a role in pituitary adenoma pathogenesis. In contrast, the corticotropinoma did not show LOH. This may be explained by contamination of the tumor sample with normal pituitary tissue, especially because it was taken from a second surgery of this originally $10 \mathrm{~mm}$ adenoma. Another possibility is that the Cushing's disease patient may have a different (i.e. not loss of 11q13 chromosomal material) second hit for the development of the pituitary tumor, such as downregulation of gene expression through promoter methylation (37) or via microRNAs (38).

One of our important findings is that we have not identified somatic mutations in the tumor samples studied. This is in accordance with previous data in the literature $(9,26,33,39)$ and with the Catalogue Of Somatic Mutations In Cancer (http://cancer.sanger. ac.uk) suggesting that somatic AIPmut does not seem to contribute in the pathogenesis of the SPA.

The likely benign AIPmut R16H (Table 2), first described by Daly and coworkers (40) in a FIPA family, was identified in an acromegaly patient diagnosed at the age of 33 years with a macroadenoma. At first, the AIPmut $\mathrm{R} 16 \mathrm{H}$ was considered a VUS, but although this mutation has been found in familial and sporadic patients, no $\mathrm{LOH}$ was identified in tumor samples, and it has been found in some control subjects, besides it has a high MAF $(33,40,41,42)$. Therefore, it is questioned whether the $\mathrm{R} 16 \mathrm{H}$ is pathogenic, and it is hypothesized that it is a rare polymorphism $(33,42,43)$.

Regarding the AIPmut R128C (c.382C > T), we found it in two acromegaly patients, and it has been previously described in two prolactinoma patients (15). In silico

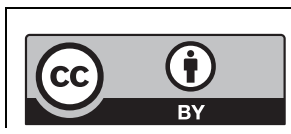

This work is licensed under a Creative Commons Attribution 4.0 International License. 
analyses predict both a benign and a deleterious mutation (Table 2), and there is lack of functional studies, restricting the conclusions about its pathogenicity. Therefore, we classified it as a VUS. Moreover, another mutation at this site $(\mathrm{R} 128 \mathrm{H})$ has been described in an acromegaly patient (44), suggesting that there might be a pathogenic role for the AIPmut R128C. The last two AIPmut (c. ${ }^{*} 14 \mathrm{C}>\mathrm{A}$ and c. ${ }^{*} 64 \mathrm{G}>\mathrm{A}$ ) are located at the $3^{\prime}$ UTR; therefore, there is no amino acid change in AIP structure (Table 2). However, the $3^{\prime}$ UTR of AIP is a known target for microRNAs (miRNAs), which are small noncoding RNAs that inhibit posttranscriptional expression of target mRNAs by binding to target sequences (45). Therefore, changes in this area could change the affinity of a specific miRNAs to its target. The two most well-studied miRNAs that bind to the AIP 3' UTR are the miR-34a and the miR-107 (14, 32, $45)$, but their binding sites do not overlap with these two new variants. The c. ${ }^{*} 64 \mathrm{G}>\mathrm{A}$ has a high MAF and is classified as likely benign at dbSNP website (Table 2 ). The c. ${ }^{*} 14 \mathrm{C}>\mathrm{A}$, on the other hand, has a low MAF provided by ExAC (Table 2) and was detected in two patients of our cohort, although no LOH have been found in the tumor sample of one of the patients harboring this AIPmut. Therefore, due to these conflicting data, we classified the AIPmut c. ${ }^{*} 14 \mathrm{C}>\mathrm{A}$ as a VUS.

Large genomic deletions of the AIP gene in mutationnegative patients can be detected by MLPA. The majority of studies that have used MLPA did not find large deletions $(12,13,16,19,24,46,47,48,49,50)$. The finding of deletions in blood DNA was restricted to 4 studies, 2 of them including only FIPA patients $(11,51)$, and other 2 studies, one including only GH-secreting adenomas, both sporadic or FIPA, that found deletions in 2 giant patients, one of them with FIPA (25), and the other one including all types of pituitary adenomas both sporadic or FIPA, that found deletion in 1 giant patient (14). In our study, MLPA analysis was restricted to pediatric and acromegaly patients with quality DNA available, with no detection of large deletions. Our finding is in agreement with previous studies of SPA $(12,13,16,24,46,47)$. Therefore, MLPA analysis may be restricted to FIPA cases, for sporadic pituitary adenoma patients diagnosed in childhood or adolescence, or even in patients with a phenotype highly suggestive of AIPmut, that were tested negative for AIPmut in sequencing analyses.

In conclusion, our AIPmut screening performed for the first time in a Brazilian population corroborates the low frequency of germline AIPmut in SPA, as previously reported in other ethnic populations. Moreover, we found two AIPmut that are only described in Brazilian patients.
We also show that special populations like patients with gigantism and patients diagnosed in childhood present a higher prevalence of AIPmut, and therefore, should be considered for screening. This allows early identification of affected carriers, when the proband is identified. Finally, we described for the first time the presence of $\mathrm{LOH}$ in a somatotropinoma from an acromegaly patient harboring an A299V AIPmut, previously classified as VUS. Finally, the diversity of AIPmut found among all the studies points to the need for more functional studies for a better understanding of the role of AIP in the pituitary tumorigenesis.

\section{Declaration of interest}

M R G has received consulting fees from Novartis, Ipsen and lonis, speaker fees from Novartis, Pfizer and Ipsen and research grants from Novartis, Ipsen and Pfizer. P B A is employed by Diagnósticos da América SA, but the company had no interference in the development of the study, and this affiliation does not alter policies on sharing data and materials.

\section{Funding}

The laboratory work was funded by a grant from Fundação de Amparo a Pesquisa do Estado do Rio de Janeiro - FAPERJ E-26/010.001967/2014 (to M R G) and from unrestricted research grants from Novartis and Ipsen (to $M R$ G). The funder Diagnósticos da América SA provided support in the form of salaries for author P B A, but did not have any additional role in the study design, data collection and analysis, decision to publish or preparation of the manuscript.

\section{Acknowledgements}

The authors would like to thank patients for accepting to take part of this study and all the neuroendocrinology team from HUCFF-UFRJ for the constant and valuable support.

\section{References}

1 Gadelha MR, Trivellin G, Hernández Ramírez LC \& Korbonits M. Genetics of pituitary adenomas. Frontiers of Hormone Research 2013 41 111-140.

2 Melmed S. Pathogenesis of pituitary tumors. Nature Reviews Endocrinology 20117 257-266. (doi:10.1038/nrendo.2011.40)

3 Vierimaa O, Georgitsi M, Lehtonen R, Vahteristo P, Kokko A, Raitila A, Tuppurainen K, Ebeling TM, Salmela PI, Paschke R, et al. Pituitary adenoma predisposition caused by germline mutations in the AIP gene. Science 2006312 1228-1230. (doi:10.1126/ science.1126100)

4 Trivellin G \& Korbonits M. AIP and its interacting partners. Journal of Endocrinology 2011210 137-155. (doi:10.1530/JOE-11-0054)

5 Swedenborg E \& Pongratz I. AhR and ARNT modulate ER signaling. Toxicology 2010268 132-138. (doi:10.1016/j.tox.2009.09.007)

6 Laenger A, Lang-Rollin I, Kozany C, Zschocke J, Zimmermann N, Rüegg J, Holsboer F, Hausch F \& Rein T. XAP2 inhibits glucocorticoid receptor activity in mammalian cells. FEBS Letters $20095 \mathbf{5 8 3}$ 1493-1498. (doi:10.1016/j.febslet.2009.03.072)

7 Tuominen I, Heliövaara E, Raitila A, Rautiainen MR, Mehine M, Katainen R, Donner I, Aittomäki V, Lehtonen HJ, Ahlsten M, et al. AIP inactivation leads to pituitary tumorigenesis through defective

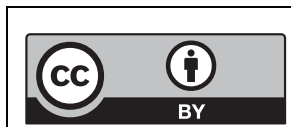

This work is licensed under a Creative Commons Attribution 4.0 International License. 
Galphai-cAMP signaling. Oncogene 201534 1174-1184. (doi:10.1038/ onc.2014.50)

8 Gadelha MR. Loss of heterozygosity on chromosome 11q13 in two families with acromegaly/gigantism is independent of mutations of the multiple endocrine neoplasia type I gene. Journal of Clinical Endocrinology and Metabolism 199984 249-256.

9 Leontiou CA, Gueorguiev M, van der puy J, Quinton R, Lolli F, Hassan S, Chahal HS, Igreja SC, Jordan S, Rowe J, et al. The role of the aryl hydrocarbon receptor-interacting protein gene in familial and sporadic pituitary adenomas. Journal of Clinical Endocrinology and Metabolism 200893 2390-2401. (doi:10.1210/ jc.2007-2611)

10 Hernandez-Ramirez LC, Martucci F, Morgan RM, Trivellin G, Tilley D, Ramos-Guajardo N, Iacovazzo D, D'Acquisto F, Prodromou C \& Korbonits M. Rapid proteasomal degradation of mutant proteins is the primary mechanism leading to tumorigenesis in patients with missense AIP mutations. Journal of Clinical Endocrinology and Metabolism 2016101 3144-3154. (doi:10.1210/jc.2016-1307)

11 Igreja S, Chahal HS, King P, Bolger GB, Srirangalingam U, Guasti L, Chapple JP, Trivellin G, Gueorguiev M, Guegan K, et al. Characterization of aryl hydrocarbon receptor interacting protein (AIP) mutations in familial isolated pituitary adenoma families. Human Mutation 201031 950-960. (doi:10.1002/humu.21292)

12 Cazabat L, Bouligand J, Salenave S, Bernier M, Gaillard S, Parker F, Young J, Guiochon-Mantel A \& Chanson P. Germline AIP mutations in apparently sporadic pituitary adenomas: prevalence in a prospective single-center cohort of 443 patients. Journal of Clinical Endocrinology and Metabolism 201297 E663-E670. (doi:10.1210/ jc.2011-2291)

13 Preda V, Korbonits M, Cudlip S, Karavitaki N \& Grossman AB. Low rate of germline AIP mutations in patients with apparently sporadic pituitary adenomas before the age of 40: a single-centre adult cohort. European Journal of Endocrinology 2014171 659-666. (doi:10.1530/ EJE-14-0426)

14 Hernandez-Ramirez LC, Gabrovska P, Dénes J, Stals K, Trivellin G, Tilley D, Ferrau F, Evanson J, Ellard S, Grossman AB, et al. Landscape of familial isolated and young-onset pituitary adenomas: prospective diagnosis in AIP mutation carriers. Journal of Clinical Endocrinology and Metabolism 2015100 E1242-E1254. (doi:10.1210/jc.2015-1869)

15 Lecoq AL, Bouligand J, Hage M, Cazabat L, Salenave S, Linglart A, Young J, Guiochon-Mantel A, Chanson P \& Kamenický P. Very low frequency of germline GPR101 genetic variation and no biallelic defects with AIP in a large cohort of patients with sporadic pituitary adenomas. European Journal of Endocrinology 2016174 523-530. (doi:10.1530/EJE-15-1044)

16 Tichomirowa MA, Barlier A, Daly AF, Jaffrain-Rea ML, Ronchi C, Yaneva M, Urban JD, Petrossians P, Elenkova A, Tabarin A, et al. High prevalence of AIP gene mutations following focused screening in young patients with sporadic pituitary macroadenomas. European Journal of Endocrinology 2011165 509-515. (doi:10.1530/EJE-11-0304)

17 Lecoq AL, Kamenický P, Guiochon-Mantel A \& Chanson P. Genetic mutations in sporadic pituitary adenomas - what to screen for? Nature Reviews Endocrinology 201511 43-54. (doi:10.1038/ nrendo.2014.181)

18 Beckers A, Aaltonen LA, Daly AF \& Karhu A. Familial isolated pituitary adenomas (FIPA) and the pituitary adenoma predisposition due to mutations in the aryl hydrocarbon receptor interacting protein (AIP) gene. Endocrine Reviews $2013 \mathbf{3 4} 239-277$. (doi:10.1210/ er.2012-1013)

19 Stratakis CA, Tichomirowa MA, Boikos S, Azevedo MF, Lodish M, Martari M, Verma S, Daly AF, Raygada M, Keil MF, et al. The role of germline AIP, MEN1, PRKAR1A, CDKN1B and CDKN2C mutations in causing pituitary adenomas in a large cohort of children, adolescents, and patients with genetic syndromes. Clinical Genetics 201078 457-463. (doi:10.1111/j.1399-0004.2010.01406.x)
20 Ramirez-Renteria C, Hernández-Ramírez LC, Portocarrero-Ortiz L, Vargas G, Melgar V, Espinosa E, Espinosa-de-Los-Monteros AL, Sosa E, González B, Zúñiga S, et al. AIP mutations in young patients with acromegaly and the Tampico Giant: the Mexican experience. Endocrine 201653 402-411.

21 Daly AF \& Beckers A. Familial isolated pituitary adenomas (FIPA) and mutations in the aryl hydrocarbon receptor interacting protein (AIP) gene. Endocrinology Metabolism Clinics of North America 201544 19-25. (doi:10.1016/j.ecl.2014.10.002)

22 Korbonits M, Storr H \& Kumar AV. Familial pituitary adenomas who should be tested for AIP mutations? Clinical Endocrinology 2012 77 351-356. (doi:10.1111/j.1365-2265.2012.04445.x)

23 Georgitsi M, De Menis E, Cannavò S, Mäkinen MJ, Tuppurainen K, Pauletto P, Curtò L, Weil RJ, Paschke R, Zielinski G, et al. Aryl hydrocarbon receptor interacting protein (AIP) gene mutation analysis in children and adolescents with sporadic pituitary adenomas. Clinical Endocrinology 200869 621-627. (doi:10.1111/ j.1365-2265.2008.03266.x)

24 Cuny T, Pertuit M, Sahnoun-Fathallah M, Daly A, Occhi G, Odou MF, Tabarin A, Nunes ML, Delemer B, Rohmer V, et al. Genetic analysis in young patients with sporadic pituitary macroadenomas: besides AIP don't forget MEN1 genetic analysis. European Journal of Endocrinology 2013168 533-541. (doi:10.1530/EJE-12-0763)

25 Schofl C, Honegger J, Droste M, Grussendorf M, Finke R, Plöckinger U, Berg C, Willenberg HS, Lammert A, Klingmüller D, et al. Frequency of AIP gene mutations in young patients with acromegaly: a registry-based study. Journal of Clinical Endocrinology and Metabolism 201499 E2789-E2793. (doi:10.1210/jc.2014-2094)

26 Barlier A, Vanbellinghen JF, Daly AF, Silvy M, Jaffrain-Rea ML, Trouillas J, Tamagno G, Cazabat L, Bours V, Brue T, et al. Mutations in the aryl hydrocarbon receptor interacting protein gene are not highly prevalent among subjects with sporadic pituitary adenomas. Journal of Clinical Endocrinology and Metabolism 200792 1952-1955. (doi:10.1210/jc.2006-2702)

27 Minnetti M \& Grossman A. Somatic and germline mutations in NETs: implications for their diagnosis and management. Best Practice and Research: Clinical Endocrinology and Metabolism 201630 115-127. (doi:10.1016/j.beem.2015.09.007)

28 Craig Rowlands J, Urban JD, Wikoff DS \& Budinsky RA. An evaluation of single nucleotide polymorphisms in the human aryl hydrocarbon receptor-interacting protein (AIP) gene. Drug Metabolism and Pharmacokinetics 201126 431-439. (doi:10.2133/dmpk.DMPK11-SC-013)

29 Richards S, Aziz N, Bale S, Bick D, Das S, Gastier-Foster J, Grody WW, Hegde M, Lyon E, Spector E, et al. Standards and guidelines for the interpretation of sequence variants: a joint consensus recommendation of the American College of Medical Genetics and Genomics and the Association for Molecular Pathology. Genetics in Medicine 201517 405-424. (doi:10.1038/gim.2015.30)

30 Perez-Rivas LG, Theodoropoulou M, Ferraù F, Nusser C, Kawaguchi K, Stratakis CA, Faucz FR, Wildemberg LE, Assié G, Beschorner R, et al. The gene of the ubiquitin-specific protease 8 is frequently mutated in adenomas causing Cushing's disease. Journal of Clinical Endocrinology and Metabolism 2015100 E997-E1004. (doi:10.1210/jc.2015-1453)

31 Toledo RA, Lourenço DM, Liberman B Jr, Cunha-Neto MB, Cavalcanti MG, Moyses CB, Toledo SP \& Dahia PL. Germline mutation in the aryl hydrocarbon receptor interacting protein gene in familial somatotropinoma. Journal of Clinical Endocrinology and Metabolism 200792 1934-1937. (doi:10.1210/jc.2006-2394)

32 Denes J, Kasuki L, Trivellin G, Colli LM, Takiya CM, Stiles CE, Barry S, de Castro M, Gadelha MR \& Korbonits M. Regulation of aryl hydrocarbon receptor interacting protein (AIP) protein expression by MiR-34a in sporadic somatotropinomas. PLOS ONE 201510 e0117107. (doi:10.1371/journal.pone.0117107)

33 Georgitsi M, Raitila A, Karhu A, Tuppurainen K, Mäkinen MJ, Vierimaa O, Paschke R, Saeger W, van der Luijt RB, Sane T, et al.
This work is licensed under a Creative Commons Attribution 4.0 International License. 
Molecular diagnosis of pituitary adenoma predisposition caused by aryl hydrocarbon receptor-interacting protein gene mutations. PNAS 2007 104 4101-4105. (doi:10.1073/pnas.0700004104)

34 Chahal HS, Chapple JP, Frohman LA, Grossman AB \& Korbonits M. Clinical, genetic and molecular characterization of patients with familial isolated pituitary adenomas (FIPA). Trends in Endocrinology and Metabolism 201021 419-427. (doi:10.1016/j.tem.2010.02.007)

35 Bolger GB, Bizzi MF, Pinheiro SV, Trivellin G, Smoot L, Accavitti MA, Korbonits M \& Ribeiro-Oliveira A Jr. cAMP-specific PDE4 phosphodiesterases and AIP in the pathogenesis of pituitary tumors. Endocrine-Related Cancer 201623 419-431. (doi:10.1530/ERC-15-0205)

36 Knudson AG Jr. Mutation and cancer: statistical study of retinoblastoma. PNAS 197168 820-823. (doi:10.1073/pnas.68.4.820)

37 Ramalho-Carvalho J, Pires M, Lisboa S, Graça I, Rocha P, BarrosSilva JD, Savva-Bordalo J, Maurício J, Resende M, Teixeira MR, et al. Altered expression of MGMT in high-grade gliomas results from the combined effect of epigenetic and genetic aberrations. PLOS ONE 20138 e58206. (doi:10.1371/journal.pone.0058206)

38 Luzi E, Marini F, Giusti F, Galli G, Cavalli L \& Brandi ML. The negative feedback-loop between the oncomir Mir-24-1 and menin modulates the Men1 tumorigenesis by mimicking the 'Knudson's second hit'. PLoS ONE 20127 e39767. (doi:10.1371/journal.pone.0039767)

39 Iwata T, Yamada S, Mizusawa N, Golam HM, Sano T \& Yoshimoto K. The aryl hydrocarbon receptor-interacting protein gene is rarely mutated in sporadic GH-secreting adenomas. Clinical Endocrinology 200766 499-502.

40 Daly AF, Vanbellinghen JF, Khoo SK, Jaffrain-Rea ML, Naves LA, Guitelman MA, Murat A, Emy P, Gimenez-Roqueplo AP, Tamburrano G, et al. Aryl hydrocarbon receptor-interacting protein gene mutations in familial isolated pituitary adenomas: analysis in 73 families. Journal of Clinical Endocrinology and Metabolism 200792 1891-1896. (doi:10.1210/jc.2006-2513)

41 Cazabat L, Libè R, Perlemoine K, René-Corail F, Burnichon N, Gimenez-Roqueplo AP, Dupasquier-Fediaevsky L, Bertagna X, Clauser E, Chanson P, et al. Germline inactivating mutations of the aryl hydrocarbon receptor-interacting protein gene in a large cohort of sporadic acromegaly: mutations are found in a subset of young patients with macroadenomas. European Journal of Endocrinology 2007 157 1-8. (doi:10.1530/EJE-07-0181)

42 Zatelli MC, Torre ML, Rossi R, Ragonese M, Trimarchi F, degli Uberti E \& Cannavò S. Should aip gene screening be recommended in family members of FIPA patients with R16H variant? Pituitary 201316 238-244. (doi:10.1007/s11102-012-0409-5)

43 Ozfirat Z \& Korbonits M. AIP gene and familial isolated pituitary adenomas. Molecular and Cellular Endocrinology 2010326 71-79. (doi:10.1016/j.mce.2010.05.001)
44 Jaffrain-Rea ML, Angelini M, Gargano D, Tichomirowa MA Daly AF, Vanbellinghen JF, D'Innocenzo E, Barlier A, Giangaspero F, Esposito V, et al. Expression of aryl hydrocarbon receptor (AHR) and AHR-interacting protein in pituitary adenomas: pathological and clinical implications. Endocrine-Related Cancer 200916 1029-1043. (doi:10.1677/ERC-09-0094)

45 Trivellin G, Butz H, Delhove J, Igreja S, Chahal HS, Zivkovic V, McKay T, Patócs A, Grossman AB \& Korbonits M. MicroRNA miR-107 is overexpressed in pituitary adenomas and inhibits the expression of aryl hydrocarbon receptor-interacting protein in vitro. American Journal of Physiology: Endocrinology and Metabolism 2012303 E708-E719. (doi:10.1152/ajpendo.00546.2011)

46 Daly AF, Tichomirowa MA, Petrossians P, Heliövaara E, JaffrainRea ML, Barlier A, Naves LA, Ebeling T, Karhu A, Raappana A, et al. Clinical characteristics and therapeutic responses in patients with germ-line AIP mutations and pituitary adenomas: an international collaborative study. Journal of Clinical Endocrinology and Metabolism 201095 E373-E383. (doi:10.1210/ jc.2009-2556)

47 Occhi G, Trivellin G, Ceccato F, De Lazzari P, Giorgi G, Demattè S, Grimaldi F, Castello R, Davì MV, Arnaldi G, et al. Prevalence of AIP mutations in a large series of sporadic Italian acromegalic patients and evaluation of CDKN1B status in acromegalic patients with multiple endocrine neoplasia. European Journal of Endocrinology 2010 163 369-376. (doi:10.1530/EJE-10-0327)

48 Pinho LK, Vieira Neto L, Wildemberg LE, Moraes AB, Takiya CM, Frohman LA, Korbonits M \& Gadelha MR. Familial isolated pituitary adenomas experience at a single center: clinical importance of AIP mutation screening. Arquivos Brasileiros de Endocrinologia e Metabologia 201054 698-704. (doi:10.1590/S000427302010000800006)

49 Cai F, Zhang YD, Zhao X, Yang YK, Ma SH, Dai CX, Liu XH, Yao Y, Feng M, Wei JJ, et al. Screening for AIP gene mutations in a Han Chinese pituitary adenoma cohort followed by LOH analysis. European Journal of Endocrinology 2013169 867-884. (doi:10.1530/ EJE-13-0442)

50 Oriola J, Lucas T, Halperin I, Mora M, Perales MJ, AlvarezEscolá C, Paz de MN, Díaz Soto G, Salinas I, Julián MT, et al. Germline mutations of AIP gene in somatotropinomas resistant to somatostatin analogues. European Journal of Endocrinology 2013168 9-13. (doi:10.1530/EJE-12-0457)

51 Georgitsi M, Heliövaara E, Paschke R, Kumar AV, Tischkowitz M, Vierimaa O, Salmela P, Sane T, De Menis E, Cannavò S, et al. Large genomic deletions in AIP in pituitary adenoma predisposition. Journal of Clinical Endocrinology and Metabolism 200893 4146-4151. (doi:10.1210/jc.2008-1003)

Received in final form 20 October 2017

Accepted 26 October 2017

Accepted preprint published online 26 October 2017 http://www.endocrineconnections.org DOI: 10.1530/EC-17-0237 (c) 2017 The authors Published by Bioscientifica Ltd

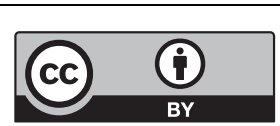

This work is licensed under a Creative Commons Attribution 4.0 International License. 